\title{
SOBRE LA SUBJETIVIDAD FEMENINA EN DETRÁS DEL ESPEJO DE JULIETA PINTO
}

\author{
About female subjectivity in Detrás del espejo by Julieta Pinto
}

\section{Carolina Sanabria*}

\begin{abstract}
RESUMEN
Los relatos que componen la obra Detrás del espejo de Julieta Pinto construyen una muestra de la narrativa contemporánea: reflexiva, intimista, onírica, donde se pierden las certezas y todo se diluye en lo que se representa como elementos naturales (niebla, río). Es un texto abundante en referencias a la subjetividad femenina, donde se acentúan elementos que la refuerzan, como los paradigmas de personajes shakesperianos o algunos elementos de los que se rodea que al mismo tiempo contribuyen a su feminización, en una reivindicación del mismo acto de escritura.

Palabras clave: literaura costarricense, Julieta Pinto, Detrás del espejo, subjetividad femenina.
\end{abstract}

\section{ABSTRACT}

The short stories which make up Julieta Pinto's Detrás del espejo constitute a sample of contemporary narrative: intimate, reflexive, oneiric, where certainties disappear and everything gets diluted in representations of natural elements (fog, the river). It is a text in which references to female subjectivity abound, for elements which reinforce it are accentuated, like the paradigms of Shakesperean characters or surrounding elements which contribute to its feminization; it is a redefinition of the act of writing itself.

Key Words: Costa Rican literature, Julieta Pinto, Detrás del espejo, female subjectivity.

Universidad de Costa Rica. Profesora. Escuela de Filología, Lingüística y Literatura. Costa Rica.

Correo electrónico: csanabriacr@yahoo.com

Recepción:8/12/15. Aceptación: 29/3/16. 
Una de las escritoras más versátiles del panorama costarricense contemporáneo es sin duda Julieta Pinto. A lo largo de su fructífera narrativa ha logrado bordar con su definido estilo ficciones que van desde el relato histórico hasta otros de corte más universal, como los que toman como punto de partida el texto bíblico, sin mencionar los del género infantil. $\mathrm{Y}$ en todos ellos puede decirse que el tono es el mismo, inclinado al intimismo reflexivo. Pero no es que la autora proceda oponiendo un tipo de una escritura distintas a la obras de talante más épico, es que la modulación se mantiene constante a lo largo de su narrativa.

Este acento, de una subjetividad microscópica y fragmentaria, se hace particularmente vivaz en algunos textos más que en otros, como es el caso de los relatos que componen Detrás del espejo (2000). La mayor parte de ellos, bastante cortos, no llegan a narrar una historia en su estructura siquiera más simple. En general, se trata de pasajes reflexivos y estampas descriptivas de una subjetividad anímica del hablante que se trasluce en lo que hace, lo que observa y en especial lo que siente, reforzado por el escaso diálogo -cuya función convencional en la narrativa es la de permitir la prolongación de la acción-. Dicho de otro modo, no todos contienen el desarrollo de una acción, como se suele concebir el relato convencional, sino que se acercan más a una función lírica, género por cierto también cultivado por la misma autora.

El tema sobre el que estos pequeños textos giran es el de la subjetividad femenina e íntima, de tipo confesional de la mujer burguesa o pequeño burguesa. La narrativa de Julieta Pinto se enmarca en la promoción de un mundo complejo y cambiante -el de su generación, que vivió la Segunda República- (Quesada 2000: 80), al tiempo que constituye una forma de irrumpir en prácticas de escritura signadas "por la precariedad debido al lugar subordinado que ocupan en la sociedad" (Fallas Arias 2013: 6). Así que siendo la escritura una práctica tradicionalmente asentada en la noción patriarcal masculina -con base en el presupuesto de la capacidad de crear vida que lleva implícita-, la estética dominante de la literatura se ha basado en el deleite sexual masculino (Gilbert y Gubar 1998: 20). Así que como es bien sabido, durante milenios las mujeres fueron privadas de la posibilidad de expresión pública, lo que explica que el tono que adopte la autora en sus escrituras sea de cercanía, de intimidad, sobre todo a partir del siglo XIX cuando la mujer cambió su papel social y disfrutó de prerrogativas nuevas en el espacio urbano, como la movilidad, el traslado y la observación (Friedberg 1993: 35-36) que deja traslucir.

En general, Pinto reivindica su propia autonomía en el vertimiento de la subjetividad vicaria de su narradora en tanto mecanismo de liberación y de conformación de un universo particular, íntimo. Esta escritura que en última instancia apunta a una autorrepresentación, relata los hechos de forma cronológica, pero también combina el recuerdo y la evocación, emergiendo de ese umbral impredecible que es la memoria donde no hay nada fijo (Fallas Arias 2013: 12). Uno de los rasgos más destacables de ese enunciador básicamente femenino (a pesar de la presencia de algunos masculinos) se aprecia en que la falta que la mueve surge de la relación frustrada con respecto a ese otro que por lo general se identifica con el varón. Sin embargo esta supuesta revitalización continúa definiéndola en función del otro masculino -y constituyendo en lo que Judith Butler ha definido como el estigma en la estructura sexual dominante por un género normativo (2007: 12)-.

El primero de los relatos, "Desafío del tiempo", gira sobre el encuentro con un desconocido narrado desde una protagonista narradora que deambula como una flaneuse ociosa en una sala de arte. La mirada, que tradicionalmente se ha vinculado al personaje masculino y al avance narrativo que adopta la focalización interna de éste (Cuvardic 2011: 86), se ejerce esta vez por un sujeto femenino, lo que revierte la norma patriarcal en la literatura y en el arte. Su mirada entonces procede a un mecanismo no dominante en la narrativa que objetiva al varón (y no a la mujer) el cual, en ese marco donde se encuentran, adquiere además la categoría de obra de arte: pasa del retrato 
de probablemente un noble del siglo XVII a un hombre que encarna una entidad ideal, como se aprecia en conversaciones y paseos por bosques idílicos en un entorno nebuloso y vago. Queda establecida entre ambos una conexión irracional, explicable sólo a partir de la teoría de las vidas anteriores, que le confiere a la historia de cierto aire de esoterismo. Se trata de una escena con remisiones ineludibles al episodio del protagonista con la misteriosa Madeleine abstraída en el cuadro de Carlotta Valdés en Vertigo (1952) de Alfred Hitchcock aunque focalizado a la inversa. El sujeto en cuestión sigue siendo una invención, alguien que no existe más que en la mente -imaginativa, desbordante, delirante- de su protagonista femenina, que sueña que parafraseando a Michelet imagina y sueña, y de esta manera termina el relato, con la disipación del extraño en la niebla.

Hay sin embargo algunos pocos casos en los que la voz se desdobla en otras como la masculina, como en "Sueño de invierno", donde la mujer es el objeto -elusivo, por cierto- sobre el cual se cifra el deseo del narrador. Es un texto que tiene la particularidad de que parece que aquí ésta no se revela, como sucede en la mayor parte de los relatos, como sujeto deseante, sino que encarna el deseo masculino. No obstante, en realidad es una estrategia de subjetivación femenina, porque la narración no responde propiamente a una construcción masculina en la dinámica de la línea del juego especular que propone el título, de desdoblamientos-. Más bien, se configura como una construcción masculina de su respectiva contraparte femenina - una que se permite imaginar, narrar, visualizar lo que desea que el hombre sienta, que es cosa distinta-. En otras palabras, esa imagen femenina corresponde en última instancia a una escisión suya.

En realidad, el recurso de materialización misma es el pretexto para tratar las formas que toma la subjetividad femenina: solitaria, abstraída, obsesiva, con una marcada falta que la lleva a desarrollar un vínculo afectivo tema que retoma en otro relato ("Solo el amor detiene el tiempo") y con el que contrasta a su esposo, como una alusión de su condición de mujer casada que vive en cómodo tedio-. De ahí que el enamoramiento de un desconocido constituya parte de la resignificación de un tópico patriarcal en la literatura, sobre todo en la lírica, con evocaciones a otros relatos de narraciones femeninas como La última niebla (1934) de María Luisa Bombal. Era un texto donde se trataba de una situación parecida, que giraba en torno a la imaginación desbordada de una mujer burguesa en medio de la rutina de un matrimonio frustrado que encuentra $-\mathrm{O}$ mejor dicho inventa- un amante ideal. En ambos relatos parece ser producto de la imaginación, y de manera más precisa, en el de Pinto es un extraño que aparece revestido entre sueños y desmemoria. La narración cobraba un tono similar en ambos casos, en medio de un clima nebuloso tejido también por ella misma donde se confundían sueño e imaginación con vigilia. Al final, la realidad aprisionante termina imponiéndose.

En todo caso, no es el único encuentro de índole esotérica que sucede a lo largo de Detrás del espejo. Otro semejante tiene lugar más adelante con el relato "Las estrellas también hablan", en el que la protagonista acude a un astrólogo sin recordar que lo había visitado dos años antes por la misma razón que está ahí. Ante este olvido de la conciencia, se sugiere la posibilidad de un desdoblamiento -que remite asimismo al efecto del espejo del título-, el cual en investigaciones no científicas se alude a experiencias vinculadas con los sueños.

Este ambiente onírico en que se produce el desdoblamiento contiene asimismo una concepción particular del tiempo que se distancia del tradicional. No es extraño encontrar detenciones puntuales del tiempo, como en la contemplación extática de la catedral, que condensa un nueva forma de cronotopo, pues "[h]abía quedado detenido en el cruce de líneas divergentes donde señorea el olvido" (Pinto 2010: 34), el cual, en acoplamiento con la música sublime, paraliza la capacidad de pensar.

El tiempo, en otros relatos, se diluye y se concentra en uno que no conoce de diferencias, "donde el pasado y el futuro se conjugan en un presente abierto" (Pinto 2000: 31), replanteando 
la idea de Faulkner de que el pasado no se logra superar porque no pasa nunca, o mejor dicho, ni siquiera es pasado, sino tan sólo una dimensión del presente que se ha extendido: "The past is never dead. It's not even past" (1973: 81). Así pues, la escritura de Pinto toma el curso radicalmente opuesto de uno de los principios sobre los que se basa la literatura costarricense -la de la arcadia tropical-, donde el pasado se plantea en términos eufóricos y el presente resulta más bien disfórico (Ovares et al. 2003: 57).

Así pues, a lo largo de Detrás del espejo se plantea esta idea de lo conocido que vuelve a elaborarse en el presente narrativo a partir de otras variaciones argumentales: un pez de un restaurante chino es el motivo para remitirse a una experiencia traumática de agresión infantil ("Miradas"), una joven revive un pasado familiar sangriento a raíz de una parálisis que le impide llevar a cabo la plasmación en la escritura ("La creación"). No resultan explicados porque no interesa: lo medular es la expresión subjetiva, la aprehensión descriptiva. En ambos casos, la detención de la mirada visual establece conexiones con una forma de percepción a partir de una intensidad tal que termina variando el objeto para volcarse a lo interno de la propia subjetividad y conduciendo a recuerdos pasados. Redunda en un procedimiento de evocación soñadora que se manifiesta como en una contemplación en profundidad donde el sujeto también toma conciencia de su intimidad: "una perspectiva de profundización para el mundo y para nosotros mismos" (Bachelard1997: 83).

No será la única ocasión del manejo de la relación con el pasado en esos términos: en esa suerte de escritura autobiográfica posterior que lleva por elocuente título el de El laberinto de los recuerdos (2010), su protagonista se dedica a la evocación de momentos intensamente dolorosos -la separación matrimonial, la muerte del propio hijo-. Es un libro que está narrado desde un presente cuya comodidad, a pesar de estar siendo intervenida quirúrgicamente, se intuye -antes que por su posición económica desahogada que no la lleva a un desafío del poder patriarcal-por la distancia temporal. En este caso la escritora se disocia al desdoblarse en una voz narrativa que elige claramente la forma de la memoria autobiográfica, a diferencia de estos relatos, en los que se enmascara tras un alter ego la mayor parte de las veces innominado.

Pero las marcas de subjetividad femenina se plasman asimismo en tópicos como la identificación con la naturaleza en distintos paisajes. La búsqueda de la naturaleza se vuelve, así pues, en "La voz del río", obsesiva, donde se interna con desesperación, como forma de plantear la categoría de universo infinito (en relación con otras variaciones como el arrobamiento prácticamente místico) en contraste con el cosmos perfecto y limitado de la urbe (Trías 2014: 168). Una impresión semejante también llega a ser producida por la creación humana en espacios que concentran puntos energéticos como la catedral en "Música del silencio", donde se enfrenta la pequeñez humana en marcos de sublimidad, como la impresionante construcción que, en conjunto con la música, crea una sensación extática, de integración con el todo-.

En "Sueño de invierno", que es otro de los pocos donde la narración se focaliza en un sujeto masculino, son los cambios climáticos (las hojas de otoño, el invierno que pintaba de blanco la campiña) los que marcan la espera de la mujer por el hombre. Esta propensión es tan codificada que alcanza hasta la mimetización, como en "Lluvia". Ahí la narradora, en su descripción de los sentidos que se confunden con el entorno natural, alcanza la identificación tan plena que no está en condiciones de atender la llegada del varón. Es como si estuviera muerta, lo que remite de nuevo a otro texto de Bombal, La amortajada (1935), en la que su respectiva protagonista, una vez muerta, manifiesta sentirse en plenitud por haberse integrado a la naturaleza. La vinculación entre la tensión anímica femenina que conduce a la protagonista a su propia disolución en un espacio natural es a este respecto de una extensísima tradición. Una de las más sobresalientes estilizaciones es la construcción ofélica, que reúne el topos delirante del personaje femenino que se hace acompañar de elementos naturales: hierbas, 
flores (como en este caso, hortensias, las flores rojas), la obsesión por el río y que contribuyen, aún más si cabe, a su feminización: la de un sujeto vulnerable, al principio en huida de esa realidad que la oprime.

Como se ha dicho, en varios relatos ese encuentro con la naturaleza está motivado por una huida, que está ligado a su condición sensible, frágil, femenina. Se puede apreciar en "Señales sin regreso", pero también en "El sortilegio", donde el personaje, en crisis, busca una huida que en este caso pretende ser definitiva, pero la sensación de lo sublime producida por el entorno montañoso reprime su intento. A lo largo de ellos se perfila un sujeto que parece uno solo porque desarrolla un único patrón de actos y emociones: deambula, pasa en constante huida, duda, teme. Son rasgos que remarcan asimismo una vulnerabilidad que se ha atribuido al género femenino, de modo que los actos del personaje pueden antojarse por momentos infundados, acaso artificiosos.

La feminización mencionada se acentúa en aditamentos de cuidado personal como el que indica el título, si bien no en todas las épocas tuvo ese sentido asociado a la coquetería y al cuido femeninos: en el siglo XVII se vinculaba con el proceso de introspección (MelchiorBonnet 1996: 155), probablemente más acorde con el sentido que se trasluce del texto de Pinto. La naturaleza de su reflejo responde a una superficie inquietante que ofrece una proximidad inexacta e imperfecta: en principio no respeta fielmente el objeto -a raíz de la inversión básica (la izquierda es la derecha y viceversa) - y crea una profundidad perturbadora -en razón del efecto de ubicuidad: aquí y a allá al mismo tiempo-, de modo que quien se contempla confunde su propia superficie y lo que ve a través de ella: "más fiel que la de una copia pintada, esta imagen no posee ni substrato ni consistencia" (Melchior-Bonnet 1996: 122). Ese irrespeto y profundidad del objeto que es y no es él al mismo tiempo, esa pérdida de densidad no sólo es condición de los personajes, sino también de la narración misma, donde todo es descrito en términos como nuboso, indefinido, incierto.
Porque son ellos los que se reflejan en ese espejo del título que devuelve una realidad distorsionada que hace que los que se miran sean distintos, otros. De nuevo, la voz narradora puede pensarse como una misma que, a raíz del efecto especular, se desdobla en otras, en este caso voces como la frágil, inconstante, vulnerable y delirante ofélica que busca la naturaleza para morir en ella. Pero más adelante, en "Desdémona", el relato incorpora un espejo del que se refleja una figura en un escenario -el cual a su vez en sí mismo contiene esa posibilidad de escindirse en otro, por la lógica de la representación misma-. Este personaje es la víctima por excelencia de los celos del marido a la que la narradora se había permitido cuestionar: "¿Sería Desdémona tan inocente como Shakespeare había querido presentarla? ¿Qué hombre puede saber lo que anida en el corazón de una mujer, esa mezcla de deseos y ataduras que le han sido impuestas impidiéndole la libertad?" (Pinto 2010: 39). La alienación de su vida matrimonial vacía y la incomprensión profesional pero doblemente masculina -del director de teatro y de su propio marido- la llevan años después a desdoblarse en el personaje literario, a ver -de nuevo de forma imaginativaen el último las facciones y las manos de Otelo que finalmente se ciñen sobre su cuello, en su habitación y no en el escenario, sin poder gritar ni liberarse. Desdémona viene a ser un paradigma - de la mujer coqueta y atrevida pero fiel y sobre todo víctima de los celos- adecuado a la mujer que en términos generales se ha desarrollado en algunos personajes anteriores de Pinto. Sin embargo, la narradora externa distancia crítica contra ese paradigma y se rebela a esa interpretación convencional para encontrarle un sentido menos victimizante.

Hacia el final del libro, este personaje narrador común recobra ánimos y fuerzas y se recupera. Así, en el antepenúltimo, "Pasado de magia y sombras", tras adentrarse en el campo, se autodefine como un "ser de violencia y odio" y se enfrenta, utilizando latigazos como respuesta, con una bruja para deshacer un hechizo: "Mi fuerza es mayor que la tuya, te obligaré a devolverme a mi 
marido" (Pinto 2010: 71). Para entonces está lejos de ser Ofelia y esa rebeldía contenida en Desdémona discurre hasta liberarse en lo que parece acercarse más a Lady Macbeth. La versatilidad de los tipos de escritura de Pinto se vuelca aquí a la conformación de los tipos de personajes, que en última instancia no dejan de ser, como se ha dicho, uno mismo: ese que se refleja en el espejo.

El último relato, "La casa de las hortensias", está focalizado desde la perspectiva de un joven narrador masculino vendedor de televisores que llega -de nuevo, en un estado de cansancio y somnolencia- a una casa desconocida de un pueblo donde una mujer ("una señora excéntrica") lo espera y acoge. El estado brumoso, nebuloso y de ensoñación que ha atravesado el libro se mantiene en este último relato, el cual, a diferencia del resto, contiene mayor desarrollo de acción. Y una vez más, para el final se reserva un nuevo desdoblamiento en el que éste termina corporeizando al hijo muerto diez años atrás, y lo que afianza este reconocimiento es la música sublime por excelencia de Mozart que interpreta. No en vano la obra del compositor austriaco, según Nicholas Till, propone una reconciliación de la humanidad con la naturaleza y lo absoluto (1994: 320), presentificada en el anterior relato, "Música del silencio". En cualquier caso, ello remite de nuevo al mencionado tratamiento del tiempo, donde los hechos definitivos del pasado reculan de manera fantástica -no aquí ya como materialización de un retrato del siglo XVII sino de un tipo aparentemente común, vendedor de televisores que sin embargo esconde una sensibilidad musical que aflora al final-. Se está ante una nueva variación de lo que sucedía en los primeros relatos, en el que la narradora se permite elaborar imaginariamente una situación deseada e inexistente pero no con un hombre misterioso -el del retrato, el desconocido-, sino con el hijo muerto. Puede por tanto decirse de los personajes femeninos de Detrás del espejo lo mismo que ha dicho en el prólogo del libro Amado Alonso de la protagonista de La última niebla, esto es, que todo lo que pasa en el texto "pasa dentro de la cabeza y del corazón de una mujer que sueña y ensueña" (en Bombal 1941: 11).

Parte de la misma subjetividad que codificadamente se ha asignado a lo femenino reside en la utilización de las evocaciones oníricas por cuanto su capacidad soñadora es parte de los mecanismos de ruptura de la represión que domina normalmente la conciencia (Freud). La narración fluye por los cauces del sueño y de la fantasía, que impiden definir la realidad. En general, los textos están teñidos de una atmósfera evanescente. Se tiende por tanto a la desaparición de lo real, subsumido por una nebulosa que se materializa en los mismos personajes, mayormente innominados -indeterminados- y en elementos naturales como la niebla misma, como también se había elaborado en el relato de Bombal, en el que "la niebla borra metafóricamente los límites imprecisos entre vida consciente e inconsciente, que es donde acontece la narración" (Méndez Rodenas : 938), como metáfora del desconcierto al que por momentos la protagonista admite no poder atribuir a ninguna razón valedera.

La niebla es un recurso que permite sugerir la dificultad del acto visual que en cambio se alude con el espejo del título. A lo largo de los relatos hay una dialéctica constante entre las imágenes de un personaje narrador femenino que se desdoblan, que se multiplican en distintas facetas -los personajes shakesperianos, la mujer en sus distintas edades y sus respectivas crisisdesde una nebulosa visión que al mismo tiempo dificulta entreverlas y menos aún distinguirlas.

Cualquier reflexión sobre la subjetividad femenina tiene que hacerse desde la descentralización del sujeto racional (Fallas Arias 2013) lo que implicaría también una perturbación de los modos de escritura tradicionales y un decantamiento por conocimientos que beben de las fuentes de la mitología. Julieta Pinto elabora su propuesta a partir de los recursos de narración -asociados, como ya se mencionó, a la dubitación, reflexividad, evocación, ensoñación- que, si bien no contienen propiamente una transgresión ni un desafío directo o explícito al sistema patriarcal, implican un adentramiento a otras 
formas alternas de narración. $Y$ si bien se considera que la escritura ha sido una práctica asociada ortodoxamente al género masculino, la suya adquiere un carácter que no evita contener cierta subversión y que centra su mayor valor en la emergencia del silencio y de la invisibilización, es decir, en el acto mismo de escritura.

\section{Bibliografía}

Bachelard, Gaston. 1997. El agua y los sueños. Ensayo sobre la imaginación de la materia. México: Fondo de Cultura Económica.

Bombal, María Luisa. 1941. La última niebla. $2^{\mathrm{a}}$ Ed.. Santiago de Chile: Nascimento.

Bombal, María Luisa. 1978. La amortajada. Argentina: Andina.

Butler, Judith. 2007. El género en disputa. El feminismo y la subversión de la identidad. Barcelona: Paidós.

Cuvardic, Dorde. 2011. "La flaneuse en la historia de la cultura", Revista de Filología y Lingüística de la Universidad de Costa Rica, 37 (1): 67-95.

Fallas Arias, Teresa. 2013. Escrituras del yo femenino en Centroamérica 1940-2002. San José, C. R.: Editorial de la Universidad de Costa Rica.

Faulkner, William. 1973. Requiem for a Nun. Harmondsword: Penguin.

Friedberg, Anne. 1993. Window Shoping. Cinema and the Posmodern. Berkeley: University of California Press.
Freud, Sigmund. 1999. La interpretación de los sueños. Madrid: Alianza.

Gilbert, Sandra \& Susan Gubar. 1998. La loca del desván. La escritora y la imaginación literaria del siglo XIX. Madrid: Cátedra.

Melchior-Bonnet, Sabine. 1996. Historia del espejo. Barcelona: Herder.

Méndez Rodenas, Adriana. 1994. "El lenguaje de los sueños en La última niebla: la metáfora del Eros", Revista Iberoamericana, LX, 168-169, julio-diciembre: 935-943.

Ovares, Flora et al. 1993. La casa paterna: escritura y nación en Costa Rica. San José, C.R.: Editorial de la Universidad de Costa Rica.

Pinto, Julieta. 2000. Detrás del espejo. Heredia, C.R.: EUNA.

Pinto, Julieta. 2010. El laberinto de los recuerdos. San José, C.R.: EUNED.

Quesada, Álvaro. 2000. Breve historia de la literatura costarricense. San José, C.R.: Porvenir.

Till, Nicholas. 1993. Mozart and the Enlightenment. Nueva York: Faber \& Faber.

Trías, Eugenio. 2014. Lo bello y lo siniestro. Barcelona: Debolsillo.

Este obra está bajo una licencia de Creative Commons Reconocimiento-NoComercial-SinObraDerivada 4.0 Internacional. 
